\title{
BMJ Open Positive and negative reasons for sickness presenteeism in Norway and Sweden: a cross-sectional survey
}

\author{
Vegard Johansen, ${ }^{1}$ Gunnar Aronsson, ${ }^{2}$ Staffan Marklund ${ }^{3}$
}

To cite: Johansen $\mathrm{V}$ Aronsson G, Marklund S. Positive and negative reasons for sickness presenteeism in Norway and Sweden: a crosssectional survey. BMJ Open 2014;4:e004123. doi:10.1136/ bmjopen-2013-004123

- Prepublication history and additional material for this paper is available online. To view these files please visit the journal online (http://dx.doi.org/10.1136/ bmjopen-2013-004123).

Received 29 September 2013 Revised 8 January 2014 Accepted 14 January 2014

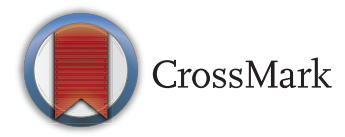

${ }^{1}$ Group for Welfare Research, Eastern Norway Research Institute, Lillehammer, Norway

${ }^{2}$ Department of Psychology, Stockholm University, Stockholm, Sweden

${ }^{3}$ Division of Insurance Medicine, Karolinska Institute, Stockholm, Sweden

Correspondence to Dr Vegard Johansen; vj@ostforsk.no

\begin{abstract}
Objectives: This article investigates various reasons for sickness presenteeism (SP), that is, going to work despite illness. The research questions asked is: What are the main reported reasons for SP in Norway and Sweden?

Design: Cross-sectional survey in Norway and Sweden. Use of binomial logistic regression analysis.

Participants: A random sample of people aged between 20 and 60 years was obtained from complete and updated databases of the Norwegian and Swedish populations. A postal questionnaire was sent to the selected individuals, with response rate $33 \%(\mathrm{n}=2843)$. 2533 workers responded to questions about SP during the last 12 months.
\end{abstract}

Primary and secondary outcome measures: The article informs about the distribution of reasons for SP in Norway and Sweden, selected by the respondents from a closed list. The article also examines which factors influence the most often reported reasons for SP.

Results: $56 \%$ of the Norwegian and Swedish respondents experienced SP in the previous year. The most frequently reported reasons for SP include not burden colleagues $(43 \%)$, enjoy work (37\%) and feeling indispensable (35\%). A lower proportion of Norwegians state that they cannot afford taking sick leave adjusted OR (aOR $0.16(95 \% \mathrm{Cl} 0.10$ to 0.22$)$ ), while a higher proportion of Norwegians refer to that they enjoy their work (aOR=1.64 (95\% $\mathrm{Cl} 1.28$ to 2.09)). Women and young workers more often report that they do not want to burden their colleagues. Managers $(\mathrm{aOR}=2.19$ (95\% $\mathrm{Cl} 1.67$ to 2.86$)$ ), highly educated persons and the self-employed more often report that they are indispensable.

Conclusions: Positive and negative reasons for SP are reported, and there are significant differences between respondents from the two countries. The response rate is low and results must be interpreted with caution.

Study design: Cross-sectional study.

\section{INTRODUCTION}

Sickness presenteeism (SP) refers to going to work despite illness. ${ }^{12}$ This concept has been a subject of steadily increasing interest since it emerged in the 1990s. ${ }^{3-5}$ Several studies in

\section{Strengths and limitations of this study}

- The sample is quite large; 2533 workers of which 1408 workers experienced sickness presenteeism (SP).

- The respondents could choose from 12 positive and negative reasons for SP.

- The response rate is low, and the responses to $\mathrm{SP}$ may suffer from recall bias.

different countries and among different occupational groups have shown that large shares of employees have gone to work when they ought to stay at home for health reasons. A British study indicated that more than $80 \%$ of general practitioners, hospital physicians and senior accountants engaged in $\mathrm{SP}^{6}$ and a similar proportion of SP was reported in a Norwegian study of physicians. ${ }^{7}$ More than $70 \%$ of the Danish core work force reported one or more episodes of SP in a year, ${ }^{8}$ and in a study of a Canadian public service organisation, more than $70 \%$ had $\mathrm{SP}^{9}$ In the Netherlands, about $60 \%$ of a national sample of workers had attended work even when they felt sick. ${ }^{10}$ Finally, $50 \%$ of the respondents in a Swedish labour force survey reported SP in $1997,{ }^{1}$ and in a study from 2000 , the proportion was $70 \% .^{11}$

Previous studies on SP have focused on three issues: the association between SP and sickness absence (SA), the consequences of SP on the productivity of organisations and the causes of SP. ${ }^{2}{ }^{4}$ First, the association between absenteeism and presenteeism is strongly positive. ${ }^{1}{ }^{3} 4$ Moreover, research results indicate that SP can cause serious health problems at a later stage e $^{12-14}$ and that several episodes of SP during the previous year are a risk factor for future SA. ${ }^{15}$

Second, American researchers have investigated the consequences of SP on the productivity of organisations. It is claimed that SP causes much more aggregate productivity loss than $\mathrm{SA}^{16}$ and that managing $\mathrm{SP}$ 
effectively could be a competitive advantage. ${ }^{17}$ It seems that SP can have an impact due to reduced work capacity, but the effects on the quantity and quality of the work performed by personnel with SP should be subject to further investigation.

Third, the causes of SP have been investigated in various Nordic studies. A Swedish study identifies different types of factors related to SP, such as reporting variable/rather poor/poor health status, facing personal financial demands, and work-related demands such as staff replacement and time pressure. ${ }^{11}$ A Finnish study concludes that $\mathrm{SP}$ is sensitive to working-time arrangements, and that those working in the private sector report SP more often than those in the public sector. ${ }^{3}$ A Norwegian study argues that there is a positive correlation between job satisfaction and rates of SP. ${ }^{7}$ In a Danish study it is found that poor health, heavy work, work versus family conflicts, social support, latitude in decision-making and obesity are characteristics among those reporting $\mathrm{SP}^{4}$

Most empirical studies on SP have focused on negative presence factors such as health problems, economic considerations, job insecurity, high workload, inability of others to take over duties, inability to adjust work demands, the need to complete unfinished jobs after returning from sick leave, negative sanctions from colleagues or management, workplace culture, work ethics, feelings of moral obligation and job satisfaction. ${ }^{1-3} 6711121819$ The present study investigates 'positive' presence factors (eg, 'enjoy my work', 'going to work was beneficial for my health', etc) and 'negative' presence factors (eg, 'can't afford taking sick leave', 'I am worried about being laid off', etc). ${ }^{12}{ }^{19}$ Using data from a cross-country study, this article describes the distribution of 12 reasons for SP in Norway and Sweden. The research question asked is: What are the main reported reasons for $S P$ in Norway and Sweden?

\section{METHODS}

This study uses data from a survey in Norway and Sweden from 2011. The purpose was to study "a normal population's" attitudes towards and experiences with SA and SP. We carried out a postal survey since this was the only financially viable option for our cross-country study. The Norwegian survey was administered by Eastern Norway Research Institute and the Swedish survey was administered by ScandInfo. The data collection was part of a research project called 'Social factors contributing to sickness absence' (SOFAC) funded by the Research Council of Norway. The Research Council of Norway had no role in study design; in the collection, analysis and interpretation of the data; in the writing of the article or in the decision to submit for publication. The data collection took 2 months; it began in the beginning of March and ended in the beginning of May.

In both countries the process of selecting the gross sample was simple random sampling from the population between 20 and 60 years of age. The potential participants included people working full-time and part-time, on parental leave and on sick leave, as well as unemployed people, students and receivers of disability pension. The selection of the gross sample in Norway was carried out by Bisnode Match It, and they have a complete and updated database of the Norwegian population. The selection of the gross sample in Sweden was carried out by ScandInfo, and they have a complete and updated database of the Swedish population. A total of 4900 Norwegians were asked to participate in the survey and 1594 responded. In total, 3800 Swedes were asked to participate and 1249 responded.

The information letter stated that the aim of the survey was to map experiences and attitudes towards sick leave among representative samples in Norway and Sweden. All respondents were anonymous to the research team. Direct personal data were not collected, and none of the respondents could be identified through a combination of background information since we asked few background variables. Finally, the information letter included information about email and telephone to the researchers in the project.

The questionnaire was designed particularly for the SOFAC project. In the pilot study in Norway, respondents used about $15 \mathrm{~min}$ to fill out the questionnaire. The questionnaire included questions on a few background variables, about the employment situation, experiences with sick leave, experiences with SP, attitudes towards sick leave in general and attitudes towards sick leave due to psychological illness and skeletal muscular disease. The full questionnaire is available on request to the research team.

Statistics Norway and Statistics Sweden are sources of factual information about the populations in Norway and Sweden, and distributions of sex, age, immigration, education level, county, centrality/peripherality and municipality size are presented annually and can be accessed online. $^{20}{ }^{21}$ To test for non-response bias, we compared known values from the population between 20 and 60 years of age (potential participants) with the values that prevail in the subgroup that answered the questionnaire. It is positive that the Norwegian and Swedish net samples were representative with regard to the proportion of immigrants, as well as representative of regional dimensions such as the size of municipality, county and centrality/peripherality. The Norwegian net sample is representative with regard to gender, while there is an overrepresentation of women in the Swedish sample. In the net samples for Norway and Sweden, those in the age group 40-60 are over-represented and those between 20 and 39 years are under-represented. The data were weighed according to age and gender in order to remedy the under-representation of young workers and men. The data are weighed according to country of origin, so the Norwegian and Swedish samples have the same influence.

Questions about SP were answered by 2533 respondents who were either working, in parental leave or in SA. Frequency of SP (the distribution of SP episodes) 
was measured by the following question: "During the last 12 months, did you go to work despite feeling so ill that you should have taken sick leave?" A total of 1408 respondents reported SP, and they selected one or more alternatives from 12 options in response to the question: "Why did you go to work although you were ill?" The response options were chosen by the research team and based on former studies about SP and SA. Some of these reasons were negative (options 1 to 5), some were positive (options 8 to 11 ) and some can be interpreted as positive and negative (options 6 and 7 ).

Option 1 Because I am worried about being laid off.

Option 2 Because I do not want to be considered lazy or unproductive.

Option 3 Because I do not want to be suspected of cheating.

Option 4 Because I am ashamed of being ill.

Option 5 Because I can't afford taking sick leave.

Option 6 Because nobody else is able to carry out my responsibilities.

Option 7 Because I do not want to burden my colleagues.

Option 8 Because I enjoy my work.

Option 9 Because going to work was beneficial for my health.

Option 10 Because I want to maintain my social network.

Option 11 Because my pride depends on not taking sick leave.

Option 12 There were other reasons that I went to work.

Binomial logistic regression has been used to detect which factors influence the four most often reported reasons for SP. Binomial logistic regression is suitable for predicting the outcome of a categorical criterion variable that can take on only two possible outcomes. Nagelkerke $R^{2}$ is an often used version of the coefficient for determination for logistic regression. Nagelkerke $R^{2}$ ranges from 0 to 1 , and it provides a gauge of the substantive significance of the model..$^{22}$

The independent variables are selected from former studies about factors influencing SP, and they include gender, ${ }^{1}{ }^{3}{ }^{4}$ age, ${ }^{4}{ }^{11}$ migratory status, ${ }^{23}$ education, ${ }^{1}{ }^{3} 11$ income, ${ }^{14}{ }^{41}$ position, type of employment ${ }^{34815}$ and country. Some respondents did not answer all the independent variables, and 1270 respondents are included in the binomial logistic regression analyses. In addition to having proven importance in previous studies of factors related to SP, the independent variables are included in the multivariate regression models since they have statistical significance for one or more of the dependent variables (ie, the four most often reported reasons for SP). All these variables were included in the model-building process:

- Age in years.

- Gender: male (reference category) and female.

- Migratory status: divided between natives (reference category), Western immigrants (comprising western Europe, Canada, the USA, Australia and New Zealand) and non-Western immigrants (comprising persons born in other countries).
- Education: divided between high educational attainment (reference category, Bachelor degree or higher) and low educational attainment.

- Income: divided between low income (reference category, $299000 \mathrm{NKr} / \mathrm{SKr}$ ), and medium/high income $(300000+\mathrm{NKr} / \mathrm{SKr}) .300000 \mathrm{NKr}$ is about $€ 36000$ and $300000 \mathrm{SKr}$ is about $€ 33000$.

- Type of employment: divided between employee in private sector (reference category), employee in public sector and self-employee.

- Employment position: divided between those who do not have a management position (reference category), and middle management/executives.

The research was carried out in accordance with the rules set by the committees for medical research ethics in Norway and Sweden, was approved by the Norwegian Social Science Data Services and conforms to the principles embodied in the Declaration of Helsinki.

\section{RESULTS}

The response rate was $33 \%$ in both countries. In the past 12 month period, $56 \%$ of the Norwegian and Swedish respondents replied that they had gone to work even though it would have been reasonable to take sick leave. In total, 37\% reported one/two episodes of SP and $19 \%$ reported three or more episodes. In the question about reasons for SP, 32\% of the respondents marked one option, 30\% marked two options and 31\% marked three or more options, and $7 \%$ referred to 'other reasons'.

Table 1 shows the distribution of reasons for SP in Norway and Sweden. In total, $43 \%$ report going to work while ill because they did not want to burden colleagues with their sick leave, $37 \%$ report that they enjoy their work and 35\% report that nobody else can carry out their responsibilities. Some respondents report that they practiced SP because they could not afford taking sick leave $(21 \%)$, that their pride depended on not taking sick leave $(17 \%)$ or that they did not want to be considered lazy or unproductive $(16 \%)$. Small proportions of respondents reported health benefits $(11 \%)$, suspected for cheating $(8 \%)$, shame $(6 \%)$, maintaining social network (4\%) and risk for being laid off $(4 \%)$.

There are major differences between Norwegian and Swedish respondents with regard to reasons for SP. Swedish respondents are over-represented among those practicing SP because they cannot afford to be on sick leave (36\% in Sweden and only $6 \%$ in Norway). Norwegian respondents are over-represented among those pointing to various 'benefits' of going to work despite illness, such as enjoying their work (44\% in Norway and $30 \%$ in Sweden), their pride depends on not taking sick leave ( $24 \%$ vs $11 \%$ ) and going to work is beneficial for their health $(17 \%$ vs $4 \%)$. In addition, Norwegian respondents are over-represented with regard to concern of being considered lazy or unproductive (21\% vs $12 \%)$. 
Table 1 Reported reasons* for sickness presenteeism during the past 12 months among random samples of Norwegian and Swedish workers between 20 and 60 years of age, 2011

\begin{tabular}{|c|c|c|c|c|}
\hline Reasons for SP & $\begin{array}{l}\text { Sweden } \\
(n=686)\end{array}$ & $\begin{array}{l}\text { Norway } \\
(n=722)\end{array}$ & $\begin{array}{l}\text { Total } \\
(n=1408)\end{array}$ & p Value \\
\hline Because I do not want to burden my colleagues & 41 & 46 & 43 & 0.059 \\
\hline Because I enjoy my work & 30 & 44 & 37 & 0.000 \\
\hline Because nobody else is able to carry out my responsibilities & 36 & 34 & 35 & 0.404 \\
\hline Because I can't afford taking sick leave & 36 & 6 & 21 & 0.000 \\
\hline Because my pride depends on not taking sick leave & 11 & 24 & 17 & 0.000 \\
\hline $\begin{array}{l}\text { Because I do not want to be considered lazy or } \\
\text { unproductive }\end{array}$ & 12 & 21 & 16 & 0.000 \\
\hline Because going to work was beneficial for my health & 4 & 17 & 11 & 0.000 \\
\hline Because I do not want to be suspected of cheating & 8 & 8 & 8 & 0.689 \\
\hline Because I am ashamed of being ill & 4 & 7 & 6 & 0.013 \\
\hline Because I want to maintain my social network & 2 & 6 & 4 & 0.000 \\
\hline Because I am worried about being laid off & 4 & 3 & 4 & 0.179 \\
\hline
\end{tabular}

We have chosen to investigate which factors influence the four most often reported reasons for $\mathrm{SP}$, as seen in table 1 .

Table 2 shows four logistic regression models. Model I concerns factors related to why people report that they take SP because they cannot afford taking sick leave has the best fit of the four models (Nagelkerke $\mathrm{R}^{2}=0.30$ ). Significantly higher rates choosing this alternative include being a Swede, not having managerial responsibilities, having low education and having low income. It is important to note that the most influential variable in model I is 'country' and not the level of income. Model II is about indispensability, and it shows almost the opposite profile and the estimated fit is the second best (Nagelkerke $\mathrm{R}^{2}=0.14$ ). Norwegians, middle managers and executives, highly educated persons, those with medium/high income, self-employed and private employed, have reported this reason to a significantly higher degree. Models III and IV show relatively low degree of model fit (Nagelkerke $\mathrm{R}^{2}=0.07$ and 0.06 , respectively). Model III concerning the option 'do not want to burden my colleagues' which was the most frequent reason given in Norway as well as in Sweden has been reported significantly more often among younger workers, among women, among natives and Western immigrants, among employees and among non-managers. Model IV concerns the option 'because I enjoy my work', and it was most frequently reported by natives, those with medium/high income and by Norwegians.

\section{DISCUSSION}

The most often reported reasons for SP were do not want to burden my colleagues, enjoy my work and nobody else is able to carry out my responsibilities. There were significant differences between respondents from the two countries: a higher proportion of Norwegian respondents point to the benefits of going to work despite illness, while a higher proportion of Swedish respondents report economic consequences of SP. Although the sample is quite large, the results must be interpreted with caution since the list of options for SP is incomplete. Another concern is the low response rate. We could suspect that workers with strong opinions or knowledge or experiences with SA and SP have been more willing to spend time answering our questionnaire than those who do not. If workers having experienced SP are represented in a higher proportion in the sample, this could result in an overestimation of SP as compared with the situation in the population. Moreover, if the participants make a nonrepresentative sample, this questions the distribution of reported reasons for SP. It should be noted that the distribution of SP is in accordance with prior studies of SP at the national level. ${ }^{18} 10$

A majority of the respondents in Norway and Sweden have experienced SP in the past year, and this finding is in accordance with former studies of SP. ${ }^{3-11}$ This study indicates that solidarity with colleagues, feeling indispensable and to enjoy the work are the highest reported reasons for SP. The results resemble studies in Denmark and the UK showing that consideration of colleagues is an often referred reason for $\mathrm{SP}^{19}{ }^{24}$ and a study in the UK indicating that SP occurs when work cannot wait or be delegated and could create extra work for colleagues. ${ }^{6}$ Some previous studies on SP have focused on negative presence factors, ${ }^{1-3} \quad 6 \quad 7 \quad \begin{array}{llllllll} & 6 & 12 & 18 & 19 & 24 & \text { but our }\end{array}$ empirical results indicate that negative presence factors (lazy, shame, laid off and cheating) are reported by few respondents.

We expected to find differences with regard to the reasons for SP in Norway and Sweden since the level of SA is presently much higher in Norway than in Sweden $^{25}$ and there are profound differences between the two countries in attitudes towards SA. ${ }^{26}$ Moreover, 
Table 2 Factors of relevance to the four most often reported reasons for sickness presenteeism among workers between 20 and 60 years of age in Norway and Sweden, 2011

\begin{tabular}{|c|c|c|c|c|}
\hline Factors & $\begin{array}{l}\text { Because I can't } \\
\text { afford taking sick } \\
\text { leave }\end{array}$ & $\begin{array}{l}\text { Model II } \\
\text { Because nobody } \\
\text { else is able to } \\
\text { carry } \\
\text { out my } \\
\text { responsibilities }\end{array}$ & $\begin{array}{l}\text { Because I do not } \\
\text { want to burden my } \\
\text { colleagues }\end{array}$ & $\begin{array}{l}\text { Because I enjoy } \\
\text { my work }\end{array}$ \\
\hline Age $(n=1270)$ & $0.99(0.98$ to 1.00$)$ & $0.99(0.98$ to 1.00$)$ & $0.99^{\star \star}(0.98$ to 1.00$)$ & $1.00(0.99$ to 1.01$)$ \\
\hline Male $(n=660,52 \%)$ & 1.00 & 1.00 & 1.00 & 1.00 \\
\hline Female $(n=610,48 \%)$ & 0.79 (0.55 to 1.12$)$ & $0.88(0.67$ to 1.16$)$ & $1.75^{\star \star}(1.35$ to 2.26$)$ & $0.95(0.73$ to 1.24$)$ \\
\hline Native $(n=1128,89 \%)$ & 1.00 & 1.00 & 1.00 & 1.00 \\
\hline Western $(n=70,5 \%)$ & $1.67(0.91$ to 3.01$)$ & $0.89(0.51$ to 1.54$)$ & 1.02 (0.62 to 1.69$)$ & $0.54^{*}(0.31$ to 0.95$)$ \\
\hline Non-Western $(n=72,6 \%)$ & 1.59 (0.89 to 2.86$)$ & $1.25(0.73$ to 2.11$)$ & $0.49^{* *}(0.29$ to 0.84$)$ & $0.79(0.47$ to 1.34$)$ \\
\hline High education $(n=437,34 \%)$ & 1.00 & 1.00 & 1.00 & 1.00 \\
\hline Low education $(n=833,66 \%)$ & $1.68^{* \star}(1.16$ to 2.44$)$ & $0.39^{\star \star}(0.30$ to 0.52$)$ & $1.22(0.93$ to 1.58$)$ & $0.8(0.65$ to 1.11$)$ \\
\hline Medium/high income $(n=819,64 \%)$ & 1.00 & 1.00 & 1.00 & 1.00 \\
\hline Low income $(n=451,36 \%)$ & $2.57^{* *}(1.81$ to 3.65$)$ & $0.74^{*}(0.55$ to 0.99$)$ & $0.98(0.74$ to 1.29$)$ & $0.67^{\star *}(0.50$ to 0.89$)$ \\
\hline Private employment ( $n=686,54 \%)$ & 1.00 & 1.00 & 1.00 & 1.00 \\
\hline Self-employment $(n=134,11 \%)$ & $1.10(0.65$ to 1.84$)$ & $1.80^{\star \star}(1.20$ to 2.69$)$ & $0.61^{*}(0.40$ to 0.93$)$ & $0.89(0.59$ to 1.34$)$ \\
\hline Public employment $(n=450,35 \%)$ & $1.27(0.88$ to 1.85$)$ & $0.57^{\star \star}(0.42$ to 0.77$)$ & $1.25(.96$ to 1.64$)$ & 0.91 (0.69 to 1.20$)$ \\
\hline Non-management $(n=874,69 \%)$ & 1.00 & 1.00 & 1.00 & 1.00 \\
\hline $\begin{array}{l}\text { Middle management/executives } \\
(\mathrm{N}=396,31 \%)\end{array}$ & $0.54^{* *}(0.36$ to 0.81$)$ & $2.19^{\star *}(1.67$ to 2.86$)$ & $0.73^{\star}(0.56$ to 0.96$)$ & $1.13(0.87$ to 1.47$)$ \\
\hline Sweden $(n=618,49 \%)$ & 1.00 & 1.00 & 1.00 & 1.00 \\
\hline Norway $(n=651,51 \%)$ & $0.16^{\star \star}(0.10$ to 0.22$)$ & $0.76^{*}(0.59$ to 0.98$)$ & $1.18(0.92$ to 1.51$)$ & $1.64^{\star \star}(1.28$ to 2.09$)$ \\
\hline Constant & -0.98 & 0.89 & 0.96 & 0.54 \\
\hline Nagelkerke $\mathrm{R}^{2}$ & 0.30 & 0.14 & 0.07 & 0.06 \\
\hline
\end{tabular}

sickness benefits in Norway are more generous than Sweden: a sick-listed person in Norway receives full compensation of the loss of income from the first day for a maximum of 364 days, whereas in Sweden the first day of SA is not compensated and from the second day the employees receive $80 \%$ compensation of the loss of income for a maximum of 364 days within a frame of 450 days. $^{27} 28$ Economic consequences of $\mathrm{SA}$ is the fourth reported reason for SP, and Swedes report that they cannot afford to be on sick leave more often than Norwegians. This finding corresponds with former studies that point out that the direct economic consequences of SA can contribute to SP. ${ }^{13} 1819$

The survey includes questions on relevant variables that enable us to control for 'competing explanations' in our assessment of cross-country differences on reported reasons for SP. Educational attainment, income level and whether one has managerial responsibilities or not were influential factors for the most common reasons for SP. Managers and highly educated persons are likely to have a high degree of control over their work tasks, to feel time pressure and to have supervisor responsibilities, and thus, they more often report that they practice SP because nobody else is able to carry out their responsibilities. Less educated persons, those with no management responsibilities and low income more often report that they cannot afford to take sick leave, illustrating that the financial loss of being absent has a greater impact on these groups. In contrast, persons with high income more often report that they practice SP because they enjoy their work. Women and young workers more often report that they practice SP because they do not want to burden their colleagues. These findings could be an indication of differences in working conditions, for example, that a higher share of women than men experience higher levels of cooperation or dependence in performing their work tasks. A competing explanation could be that women and young workers are simply more concerned with relations at work than men and older workers.

More than half of the workers in the study experienced SP in the previous year, but it might be objected that we do not know if there is a large variation between individual's in terms of threshold to report 'should have taken sick leave'. Future studies could investigate what symptoms people who experience SP refer to and whether there are large differences in the seriousness of their illness. Although the study indicates that differences in compensation system between the two countries, educational attainment and position are influential factors for reasons for SP, further research is needed to understand and explain such differences, as well as the consequences of SP in a shorter and longer term.

Response rates tend to be very low for postal questionnaires. ${ }^{29}$ To increase the response rate, the length of the 
questionnaire was kept quite short (4 pages and 60 questions), a postal follow-up including questionnaire was sent, the return envelope was prepaid and the information letter stressed the benefits of the study to society. The quality of postal addresses provided by Bisnode Match It and ScandInfo was good, since less than 300 letters were returned (3\% of the gross sample). In retrospect, various strategies could have been considered to increase the response rate and improve the quality of our study: monetary or non-monetary incentives, personalised questionnaires and letters, contacting participants before sending the questionnaires and more than one follow-up. ${ }^{29}$

It is difficult to make conclusions about the accuracy of our survey, and the responses to questions on SP might have been influenced by recall bias. Another issue of concern is response bias, and some studies have shown that employees tend to under-report their SA. ${ }^{30}$ It could be that data on SP suffer from under-reporting or overreporting, but this study did not control for this possibility.

The fact that there are differences between Norway and Sweden where larger shares in Sweden and poor people claim that they use SP because they cannot afford to be on sick leave may indicate that the Swedish social security system is unable to cover all individuals with a health problem in an equal way. Still, it is important to be clear that other reasons than the social security system could matter for these differences. When respondents report that they practice SP because they enjoy their work, this may generally be seen as unproblematic. However, several studies have found that frequent use of SP may lead to future health problems ${ }^{4}{ }^{12-14}$ and employers and occupational health services may therefore regard this as an early indicator of reduced productivity and later SA.

Contributors VJ, GA and SM were involved in writing the manuscript. They also designed and monitored data collection, and cleaned and analysed the data.

Funding This work was supported by the Norwegian Research Council (grant number 193612).

Competing interests None.

Ethics approval Norwegian Social Science Data Services.

Provenance and peer review Not commissioned; externally peer reviewed.

Data sharing statement No additional data are available.

Open Access This is an Open Access article distributed in accordance with the Creative Commons Attribution Non Commercial (CC BY-NC 3.0) license, which permits others to distribute, remix, adapt, build upon this work noncommercially, and license their derivative works on different terms, provided the original work is properly cited and the use is non-commercial. See: http:// creativecommons.org/licenses/by-nc/3.0/

\section{REFERENCES}

1. Aronsson G, Gustafsson K, Dallner M. Sick but yet at work. An empirical study of sickness presenteeism. J Epidemiol Community Health 2000;54:502-9.

2. Johns G. Presenteeism in the workplace: a review and research agenda. J Organ Behav 2010;31:519-42.

3. Böckerman P, Laukkanen E. What makes you work while you are sick? Evidence from a survey of workers. Eur J Public Health 2010;20:43-6.
4. Hansen CD, Andersen JH. Sick at work-a risk factor for long-term sickness absence at a later date? J Epidemiol Community Health 2009;63:397-402.

5. Vingård $\mathrm{E}$, Alexanderson $\mathrm{K}$, Norlund $\mathrm{A}$. Chapter 10. Sickness presence. Scand J Public Health 2004;32:216-21.

6. McKevitt C, Morgan M, Dundas R, et al. Sickness absence and 'working through' illness: a comparison of two professional groups. J Public Health Med 1997;19:295-300.

7. Rosvold EO, Bjertness E. Physicians who do not take sick leave: hazardous heroes? Scand J Public Health 2001;29:71-5.

8. Hansen CD, Andersen JH. Going ill to work-what personal circumstances, attitudes and work-related factors are associated with sickness presenteeism? Soc Sci Med 2008;67:956-64.

9. Caverley N, Cunningham JB, MacGregor JN. Sickness presenteeism, sickness absenteeism, and health following restructuring in a public service organization. J Manag Stud 2007;44:304-19.

10. Vroome E. Prevalence of sickness absence and 'presenteeism': http://eurofound.europa.eu/ewco/2006/07/NL0607019I.htm (accessed 17 Mar 2012).

11. Aronsson G, Gustafsson K. Sickness presenteeism: prevalence, attendance-pressure factors, and an outline of a model for research. J Occup Environ Med 2005;47:958-66.

12. Taloyan M, Aronsson G, Leineweber C, et al. Sickness presenteeism predicts suboptimal self-rated health and sickness absence: a nationally representative study of the Swedish working population. PLOS ONE 2012;7:e44721.

13. Kivimäki M, Head J, Ferrie JE, et al. Working while ill as a risk factor for serious coronary events: the Whitehall II study. Am J Public Health 2005;95:98-102.

14. Gustafsson K, Marklund S. Consequences of sickness presence and sickness absence on health and work ability - a Swedish prospective cohort study. Int J Occup Med Environ Health 2011;24:153-65.

15. Bergström G, Bodin L, Hagberg J, et al. Sickness presenteeism today, sickness absenteeism tomorrow? A prospective study on sickness presenteeism and future sickness absenteeism. J Occup Environ Med 2009;51:629-38.

16. Collins JJ, Baase CM, Sharda CE, et al. The assessment of chronic health conditions on work performance, absence, and total economic impact for employers. J Occup Environ Med 2005;47:547-57.

17. Hemp P. Presenteeism: at work-but out of it. Harv Bus Rev 2004;82:49-58

18. Lovell V. No time to be sick: why everyone suffers when workers don't have paid sick leave. Washington, DC: Institute for Women's Policy Research, 2004.

19. Hansen CD. 'Making a virtue' of going ill to work-reflections on the necessity of everyday workplace 'suffering'. Tidsskrift for Forskning Sygdom og Samfund 2010;7:69-88.

20. Statistics Norway. Statistics Norway-official statistics about Norwegian society since 1876. 2013. http://www.ssb.no/en/forside; jsessionid=7DD320ACBC7AE638FDAFC68DA7DD52FF kpld-as-prod03

21. Statistics Sweden. Statistics Sweden. 2013. http://www.scb.se/ default_2154.aspx

22. Field A. Discovering statistics using IBM SPSS statistics. London: Sage Publications, 2013.

23. Agudelo-Suárez AA, Benavides FG, Felt E, et al. Sickness presenteeism in Spanish-born and immigrant workers in Spain. BMC Public Health 2010;10:791.

24. Grinyer A, Singleton V. Sickness absence and 'working through' illness: a comparison of two professional groups. Health Risk Soc 2000;2:7-21.

25. Berge C. Internasjonal sammenligning av sykefravær (International comparison of sickness absence). Økonomiske Analyser 2012;2:24-9.

26. Dahl SÅ, Holmås TH, Skjeret F. En kartlegging av holdninger til sykefravær i Norden (Attitudes towards sickness absence in the Nordic countries). Oslo: Institute for Research in Economics and Business Administration, 2007.

27. Ministry of Labour and Social Inclusion. The Norwegian Social Insurance Scheme 2011. Oslo: Ministry of labour and social inclusion, 2011.

28. Government proposition no.136. En reformerad sjukskrivningsprocess för ökad återgång i arbete (A reformed sick leave for increased return to work). Stockholm: Ministry of Health and Social Affairs, 2008.

29. Edwards $\mathrm{P}$, Roberts I, Clarke $\mathrm{M}$, et al. Increasing response rates to postal questionnaires: systematic review. BMJ 2002;324:1183.

30. van Poppel $M$, de Vet $H$, Koes $B$, et al. Measuring sick leave: a comparison of self-reported data on sick leave and data from company records. Occup Med 2002;52:485-90. 